\title{
Compreendendo o significado de estar hospitalizado no cotidiano de crianças e adolescentes com doenças crônicas
}

\author{
Understanding the meaning of being hospitalized in daily lives of children \\ and teenager with chronic diseases \\ Comprendiendo el significado del estar hospitalizado en el cotidiano de niños \\ y adolescentes con enfermedades crónicas
}

\begin{abstract}
Juliana Homem da Luz', Jussara Gue Martini"
' Universidade Federal de Santa Catarina, Centro de Ciências da Saúde, Departamento de Enfermagem, Programa de PósGraduação em Enfermagem (Doutoranda). Florianópolis-SC, Brasil.

"Universidade Federal de Santa Catarina, Centro de Ciências da Saúde, Departamento de Enfermagem, Programa de PósGraduação em Enfermagem. Florianópolis-SC, Brasil.
\end{abstract}

Submissão: 23-04-2011 Aprovação: 29-11-2012

\section{RESUMO}

O estudo buscou compreender o significado da hospitalização para crianças e adolescentes com doenças crônicas, fundamentado no Interacionismo Simbólico, desenvolvido a partir da Pesquisa Convergente Assistencial de abordagem qualitativa, cujos participantes foram uma criança e três adolescentes. Os dados foram coletados através do processo de interação em enfermagem, observação participante, escuta sensível e desenho infantil. O significado da hospitalização expressou doença, distância de casa, dor, tristeza, sofrimento, choro, nervosismo, agressividade, perda da liberdade, bem como tratamento, cura, apoio, amigos, reciprocidade com a natureza e "experiências agradáveis" através do cuidado, paixão, amor, felicidade e brincadeiras. Destacou-se a capacidade dos participantes em transformar o olhar da situação na qual estão inseridos, expressos em seus desenhos, permeados de significados e lições de vida.

Descritores: Hospitalização; Criança; Adolescente; Doença crônica; Enfermagem.

\section{ABSTRACT}

The study tried to understand the meaning of hospitalization for children and teenagers with chronic diseases substantiated on Symbolic Interactionism and developed from the qualitative Assistential Converging Research whose participants were a child and three teenagers. Data collection took place through a nursing interaction process, participating observation, sensible listening and child drawing. During the analysis, the meaning of hospitalization was expressed as being ill, away from home, feeling pain, sadness, suffering, wishing to cry, nervousness, aggressiveness and losing freedom. It was also understood as treatment, cure, support, friends, reciprocity with nature and "pleasant experiences" through care, passion, love, happiness and games. The participants' ability to show their view of the situation in which they are inserted was highlighted in their drawings, imbued with meanings and life lessons. Key words: Hospitalization; Children; Teenager; Chronic Disease; Nursing.

\section{RESUMEN}

El estudio buscó comprender el significado de la hospitalización para niños y adolescentes con enfermedades crónicas, fundamentado en el Interaccionismo Simbólico y desarrollado a partir de una Investigación Convergente Asistencial de abordaje cualitativa cuyos participantes fueron un niño y tres adolescentes. La cosecha de datos fue realizada a través del proceso de interacción en enfermería, observación participante, escucha sensible y dibujo infantil. El significado de hospitalización ha expresado el estar enfermo, lejos de casa, sentir dolor, tristeza, sufrimiento, ganas de llorar, nervosismo, agresividad e pérdida de libertad, pasando a ser comprendido también como tratamiento, cura, apoyo, amigos, estar en reciprocidad con la naturaleza y "experiencias agradables" a través del cuidado, pasión, amor, felicidad y juegos. La capacidad de los participantes de transformar su mirar de la situación donde están inseridos fue expresada en sus dibujos, permeados de significados y lecciones de vida.

Palabras clave: Hospitalización; Niños; Adolescentes; Enfermedades Crônicas; Enfermería.

Extraído da dissertação de Mestrado intitulada "Do horror ao amor: compreendendo o significado de estar hospitalizado no cotidiano de crianças e adolescentes com doenças crônicas", apresentada, em 2009, à Universidade Federal de Santa Catarina. Florianópolis-SC, Brasil. 


\section{DESENHANDO A TRAJETÓRIA}

O interesse em desenvolver este estudo na área de pediatria emergiu das interações vivenciadas por uma das pesquisadoras durante o estágio curricular desta disciplina na graduação, onde aconteceu o primeiro contato com o lúdico e o imaginário no cotidiano da hospitalização e da prática de cuidado em enfermagem pediátrica.

Posteriormente, durante a prática profissional, surgia o interesse nas interações que ocorrem no ambiente hospitalar e que são vivenciadas por crianças e adolescentes com doenças crônicas. As várias internações tornam os doentes crônicos mais frágeis e, ao mesmo tempo, mais exigentes quanto à assistência recebida. É imprescindível que os profissionais cuidadores tenham esse conhecimento e o utilizem ao planejar e executar suas ações de cuidados a essas crianças e suas famílias, pois a maneira como a criança percebe a doença e a hospitalização está ligada diretamente ao seu processo de restabelecimento e resultará em sentimentos que devem ser considerados durante o cuidado de enfermagem. O cuidado à criança engloba a técnica e os conhecimentos relacionados às patologias, mas também o cuidado como um todo, contemplando o físico, o emocional e a família ${ }^{(1-4)}$.

Diante dessa realidade, percebemos que precisávamos ultrapassar os limites da prática de cuidado, impostos, muitas vezes, pela rotina hospitalar e estender o nosso olhar para além do cuidado físico. Como enfermeiras e parte integrante desse cotidiano, sentimos a necessidade de conhecer um pouco mais sobre essas questões, e, principalmente, escutar o que as crianças e os adolescentes tinham a dizer. A escuta sensível apóia-se na empatia, onde o pesquisador deve saber sentir o universo afetivo, imaginário e cognitivo do outro para poder compreender de dentro suas atitudes, comportamentos e sistema de ideias, de valores, de símbolos e de mitos. O ouvinte sensível não julga, não mede, não compara, mas compreende as opiniões dos outros ${ }^{(5)}$.

Fundamentadas na abordagem da escuta sensível, encontramos os desenhos do adolescente RR. Ao olharmos para aquelas imagens enxergamos um mundo de significados permeando entre o horror e o amor, e que emergiram das interações do adolescente RR com o cotidiano do seu cuidado e da sua hospitalização. Assim, o desenho de RR motivou-nos a realizar esta pesquisa, abordando o lúdico e viabilizando a expressividade de crianças e adolescentes com doenças crônicas no cotidiano da hospitalização através de desenhos.

O desenvolvimento do desenho infantil traz mudanças significativas que, no início, referem-se à passagem dos rabiscos iniciais da "garatuja" para construções mais ordenadas, surgindo a partir daí os primeiros símbolos. Com o passar do tempo, as garatujas, que antes eram o prolongamento de movimentos rítmicos de ir e vir transformam-se em formas definidas apresentando maior ordenação, podendo estar se referindo a objetos naturais, imaginários ou mesmo a outros desenhos. Nessa evolução, o desenho passa a ter formas mais estruturadas, onde "a criança desenvolve a intenção de elaborar imagens no fazer artístico". A criança, inicialmente, trabalha com a hipótese de que através do desenho pode imprimir tudo o que sabe sobre o mundo, no entanto, no decorrer da simbolização ela "incorpora progressivamente regularidades ou códigos de representação das imagens do entorno, passando a considerar a hipótese de que o desenho serve para imprimir o que vê". O desenho como possibilidade de brincar, o desenho como possibilidade de falar, de registrar, marca o desenvolvimento da infância. E assim, desenhando, a criança cria e recria, suas formas expressivas, integradas à percepção, imaginação, reflexão e sensibilidade, que podem ser apropriadas pela leitura simbólica de outras crianças e adultos ${ }^{(6)}$.

Acreditamos na contribuição desta pesquisa para a construção de conhecimento na área de enfermagem pediátrica, principalmente no que diz respeito à qualidade do cuidado prestado às crianças e aos adolescentes, expressos nos significados que esses atribuem ao cotidiano da hospitalização. Com base nesse contexto, o presente estudo teve como questão norteadora: Quais os significados que crianças e adolescentes com doenças crônicas atribuem ao cotidiano da hospitalização? E como objetivo geral: Compreender o significado de estar hospitalizado no cotidiano de crianças e adolescentes com doenças crônicas.

\section{COLORINDO O CAMINHO PERCORRIDO}

A partir de nossas crenças e valores sobre a prática de cuidado em enfermagem pediátrica e o cotidiano da hospitalização infantil, integramos as cores do Interacionismo Simbólico para colorir o caminho percorrido através da pesquisa convergente assistencial (PCA) de abordagem qualitativa ${ }^{(7-10)}$.

Guiadas por essas ideias, fomos à busca de uma metodologia, ou seja, "de um caminho e instrumental próprio para a abordagem da realidade"(10). Assim, encontramos o Processo de Interação em Enfermagem (PIE), entendido como um processo dinâmico e flexível, que aproxima as pessoas com o seu cotidiano, ao mesmo tempo em que tem o objetivo de dar significado aos sentimentos, crenças e valores de cada um, buscando identificar semelhanças e diferenças, para um agir recíproco, cuja finalidade é construir com o outro um cuidado de enfermagem sensível durante o processo de hospitalização ${ }^{(11)}$.

O processo de interação em enfermagem integrou quatro momentos: $1^{\circ}$ Momento - Propondo e realizando o cuidado com crianças e adolescentes que vivenciam o cotidiano da doença crônica e da hospitalização; $2^{\circ}$ Momento - Conhecendo o cotidiano e as interações; $3^{\circ}$ Momento - Definindo a situação do cotidiano e do cuidado; e o $4^{\circ}$ Momento - Repensando sobre o cotidiano e o cuidado.

A escolha dos sujeitos incluiu os seguintes critérios: ser criança e adolescente na faixa etária de 7 a 16 anos, que vivencia a doença crônica e tem um histórico de pelo menos uma internação anterior. Participaram deste estudo uma criança com leucemia e três adolescentes, sendo dois com insuficiência renal crônica e um com osteogênese imperfeita, que vivenciam o cotidiano da doença crônica e da hospitalização, cujos nomes verdadeiros foram preservados e substituídos por outros escolhidos pela própria criança e adolescentes. 
O Hospital Infantil Joana de Gusmão (HIJG) foi o local escolhido para o desenvolvimento da pesquisa por ser a instituição na qual trabalha uma das pesquisadoras. Essa instituição está situada em Florianópolis - Santa Catarina (SC) e é vinculada à Secretaria de Estado da Saúde.

A coleta de dados foi realizada no segundo semestre de 2008, a partir de encontros individuais com os sujeitos, utilizando a técnica da observação participante, e tendo como estratégias o desenho infantil (cada participante fez três desenhos intitulados respectivamente: a primeira imagem do HIJG, quem cuida de mim no hospital e como eu vejo essas pessoas, como eu vejo o HIJG hoje) e a escuta sensível que permeou todos os momentos da investigação. Os registros foram feitos por meio de máquina fotográfica e diário de campo. A análise dos dados seguiu os quatro processos indicados pela PCA: apreensão, síntese, teorização e transferência ${ }^{(9)}$, enquanto que a interpretação foi guiada pela descrição dos desenhos trazidos pela própria criança ou adolescente, isto é, após o desenho, conversávamos sobre o que foi desenhado. Logo, eles descreviam os desenhos e ao término da descrição, faziam-se os questionamentos que se julgava necessário. Desse modo, a conversa foi gerada em torno dos questionamentos provocados pelos desenhos com a intenção de fazê-los refletir, bem como repensar sobre a prática de cuidado e o cotidiano da doença crônica e da hospitalização. Além disso, a interpretação dos dados foi fundamentada no Interacionismo Simbólico, uma referência para enfermagem pediátrica, já que a teoria permite compreender a experiência infantil, nos mais diferentes cenários da saúde, através dos sentidos e práticas interativas entre a criança e seu cotidiano de cuidado, bem como pela interação dessas com familiares, profissionais da saúde e outras crianças ${ }^{(12)}$.

Esta pesquisa respeitou os princípios definidos na Resolução 196/96 do Conselho Nacional de Saúde e os princípios do Código de Ética Profissional para normatizar as atividades de pesquisa e intervenções envolvendo seres humanos ${ }^{(13)}$, sendo submetida e aprovada pelo comitê de ética em pesquisa CEP/HIJG sob parecer no 093/2008.

\section{UMA COR, DUAS CORES, TODAS ELAS, COMPREENDEN- DO O SIGNIFICADO DE ESTAR HOSPITALIZADO NO COTIDIANO DE PRI, DIEGO, GEANDRA E EMANUELLE}

Consideramos que o ponto de partida para a compreensão do significado de estar hospitalizado no cotidiano de Pri, Diego, Geandra e Emanuelle, está no comportamento humano, ou melhor, no processo interpretativo, em que primeiro a pessoa interage consigo mesma indicando para si as coisas significativas, para em seguida a interpretação passar a significar a forma de manipulação dos significados, onde a pessoa seleciona, checa, suspende, reagrupa e transforma os significados sob o olhar da situação na qual está inserida, dando direção a sua ação ${ }^{(8)}$.

\section{A. Estar hospitalizado significa...}

Ao analisarmos os significados encontrados, percebemos logo a sintonia desses tanto com os pressupostos e os conceitos sensíveis trazidos pelo Interacionismo Simbólico, quanto com os aspectos que envolvem o comportamento e a resposta da criança e do adolescente frente ao cotidiano da doença crônica e da hospitalização.

Esse cotidiano é permeado por diferentes significados que estão expressos nos desenhos e nas falas de Pri, Diego, Geandra e Emanuelle. Inicialmente, o significado de estar hospitalizado apresenta-se pela vivência de experiências desagradáveis, tais como:

\section{Estar doente}

Vim para o hospital porque estava doente... passei mal, estava com paralisia no lado direito do corpo e a pressão alta... (Pri).

(...) estava com febre. (Emanuelle).

\section{Longe de casa}

Vim para o hospital triste, porque estava longe de casa... só sei que não gosto de ficar longe de casa... (Pri).

\section{Exposto a procedimentos dolorosos}

Tem o médico, a cama que eu estou deitada para fazer madite... (Geandra).

Desenhei o primeiro dia que internei no hospital, na unidade de adolescente, para fazer biópsia óssea... só fico um pouco nervoso ainda quando é para fazer cirurgia. (Diego).

Estava chorando e a enfermeira pegando a minha veia. Fui picada três vezes... (Emanuelle).

\section{Ficar triste, sofrer, ter vontade de chorar}

Neste desenho, sou eu chorando... Meu coração estava triste... o primeiro coração, que é o menor, é de quando eu cheguei ao hospital, estava apertado, sofrendo... (Pri).

Eu estou triste e o meu coraçãozinho está chorando. (Geandra).

\section{Ficar nervoso e responder com agressividade}

Eu estava muito nervoso, o pai deu lápis e papel para eu desenhar, mas estava tão nervoso que joguei tudo no chão. (Diego).

\section{Perder a liberdade}

(...) de não poder sair para nada. (Pri).

Os sinais como irritabilidade, choro, medo, lamentos, gestos e apatia demonstrados pelas crianças hospitalizadas devem ser valorizados, uma vez que podem ser indicativos da 
necessidade de acolhimento e de segurança ${ }^{(3)}$. O choro é o símbolo mais evidente da tristeza, do desamparo, da carência, bem como, da emoção e do desabafo, uma vez que simboliza o "colocar para fora", expressando seu estado, seus sentimentos e suas reações. A agressividade que se fez presente está cada vez mais comum em nossas crianças como uma forma de chamar a atenção e dizer "olha, eu existo, preciso de você?", de outro modo, a agressividade pode simbolizar um desabafo ou uma imitação ${ }^{(14)}$.

Esses significados atribuídos ao cotidiano da hospitalização remetem-nos à ideia de que o hospital é um ambiente permeado por novas e desagradáveis sensações corporais. No entanto, a partir do processo de interação em enfermagem com os sujeitos participantes, observamos que esses significados foram sendo checados, reagrupados e transformados ao longo das interações dos sujeitos frente ao cotidiano do cuidado e da hospitalização no qual estão inseridos; de tal modo que a criança e os adolescentes passaram a perceber o hospital também como um ambiente de cuidado. A partir desse momento, o significado de estar hospitalizado é compreendido como:

\section{Ter possibilidades de tratamento e cura}

\section{(...) estou fazendo o tratamento (Pri).}

Acho que tem haver com o cuidado, ser curada... (Geandra). (...) agora com o medicamento estou melhorando (Emanuelle).

\section{Ter apoio para enfrentar a doença e a hospitalização}

\section{(...) ao meu lado está a mãe sentada na cadeira (Geandra).}

(...) eu estou no meio de mãos dadas com a mãe... (Emanuelle).

Aqui desenhei um coração e coloquei quem cuida de mim, quem me ajuda. (Diego).

Ser cuidado por enfermeiros, médicos, outros profissionais e pela família

(...) já o segundo coração, que é o maior, estão as pessoas que cuidam de mim aqui... (Pri).

Aqui desenhei um coração e coloquei quem cuida de mim... o pai, a mãe, os médicos, os enfermeiros... (Diego).

Coloquei o nome das pessoas, enfermeiros que cuidam bem de mim e que eu gosto... (Geandra).

\section{Fazer novas amizades}

Não sei, acho que é porque fiz amizades... (Pri).

\section{(...) e os amigos do quarto (Diego).}

O apego e a identificação com as pessoas foram simbolizados, através do pai, da mãe, dos amigos do quarto, da equipe de saúde e dos profissionais de outras áreas. "Mãe, pai, professora, avós, heróis... permanecem no corpo e na alma durante a nossa vida, a escola da vida, do amor, da entrega, o porto seguro, o calor, a amainar da dor"(14).

E assim, as imagens que antes expressavam o estar doente, longe de casa, exposto a procedimentos dolorosos, triste, sofrendo com vontade de chorar, trazem outros símbolos e significados construídos nas interações entre os sujeitos participantes, a equipe de enfermagem, demais profissionais, amigos e família no cotidiano do cuidado e da hospitalização. Podemos dizer, então, que estar hospitalizado também significa vivenciar "experiências agradáveis" através do cuidado, da paixão, do amor, da felicidade e de brincadeiras.

Eu desenhei que agora o hospital está alegre, eu vejo o hospital alegre e o coração tem a ver com amor (Geandra).

Fiz esse desenho parecido com o primeiro, mais este está diferente porque estou bem. Hoje vejo o hospital com amor (Pri).

(...) meninos brincando, duas meninas e um menino no balanço... (Emanuelle).

\section{(...) brincar e porque as pessoas me deixam alegres. (Geandra).}

Porque como eu escrevi, hoje vejo o hospital mais feliz que antes... (Emanuelle)

O cuidado mostrou-se complexo, dinâmico, flexível e criativo $^{(11)}$. Os corações desenhados simbolizaram, ao mesmo tempo, a tristeza, o sofrimento, a dor, a alegria, a felicidade, a paixão, o amor, as relações pessoais e o cuidado. $\mathrm{O}$ coração humano é considerado a sede de nossos sentimentos, das emoções, da consciência, bem como a natureza ou a parte emocional do indivíduo, como oposição a parte intelectual.

As brincadeiras que foram trazidas remetem-nos à importância do lúdico no mundo da criança e do adolescente, que se intensifica no cotidiano da doença e da hospitalização. "A arte é uma forma de brincar e o brincar é uma forma de arte. Saia para brincar agora e você vai compreender tudo o que já foi dito, escrito e pesquisado sobre o brincar..." A arte, seja do tipo que for, simboliza um canal de expressão para os nossos sentimentos, nossa alma, nosso momento específico ${ }^{(14)}$.

A doença e a hospitalização interferem na capacidade emocional da criança, o brincar surge então, como um instrumento utilizado para transformar esse cotidiano, pois modifica o mundo imaginário dela, fazendo com que haja uma oscilação entre este mundo e o mundo real, superando, dessa forma, as barreiras da doença. Nesse momento, o brincar passa a ser visto como um espaço terapêutico que é capaz de promover a continuidade do desenvolvimento infantil, como também a possibilidade de, através dele, a criança hospitalizada elaborar melhor esse momento específico em que vive ${ }^{(3-4)}$. 
Além dos significados apresentados até aqui, durante todo o processo de interação com os sujeitos participantes, ficou evidente que o significado de estar hospitalizado emergiu também das interações desses sujeitos com o ambiente no qual estão inseridos. Desse modo, a influência do ser humano sobre a natureza e vice-versa mostra-se quando estar hospitalizado significa:

\section{Estar em reciprocidade com a natureza}

Desenhei um céu bonito com passarinhos é a felicidade. Escrevi que hoje vejo o hospital mais feliz do que da primeira vez... o pai também está na área de sol admirando a paisagem... o céu está colorido, tinha pássaros voando e o sol iluminando (Emanuelle).

(...) as árvores e frutas murchando, tem nuvem, vento e a florzinha também está murcha e a borboleta caindo. Eles estavam tristes assim como eu... tem as árvores, a florzinha, as frutas, o sol, tudo colorido e bonito porque estou bem (Pri).

Desenhei um jardim cheio de crianças especiais. O jardim é todo o hospital... vejo o hospital como um jardim bem bonito (Diego).

A natureza foi simbolizada como uma "parceira" que está junto a nós, possuindo também sensibilidade. Dessa maneira os adolescentes utilizaram a natureza para se expressarem, valorizando o sensível e a comunicação, denominado de ética da estética ${ }^{(15)}$.

Os significados da hospitalização trazidos por Pri, Diego, Geandra e Emanuelle, apresentam similaridade com os desenhos do adolescente $\mathrm{RR}$, especialmente no que diz respeito à transfiguração da imagem do hospital que, inicialmente, mostrava-se pelo horror e pela vivência de experiências desagradáveis, passando para imagens de amor e pela vivência de "experiências agradáveis".

Tudo isso, reforça a ideia de que as crianças e os adolescentes com doenças crônicas, participantes deste estudo, são um grupo da sociedade humana que busca o seu viver e constrói seus símbolos significativos a partir das interações com os membros da família, com os outros, o mundo externo e frente ao cotidiano da hospitalização em que estão inseridos; e que a hospitalização faz parte do cotidiano destas crianças e adolescentes que vivenciam a doença crônica, bem como de seus familiares; onde a interação é fundamental para que a equipe de enfermagem compreenda o significado de estar hospitalizado e, a partir daí, encontre diferentes maneiras de cuidar da criança, do adolescente e de sua família; uma vez que as interações vivenciadas por crianças e adolescentes com doenças crônicas no cotidiano de seu cuidado irão interferir nos significados atribuídos por esses à hospitalização; ao mesmo tempo em que o cuidado que expressa afeto e sensibilidade pode contribuir para uma imagem positiva da hospitalização e da equipe de saúde.

\section{OS RETOQUES FINAIS}

Durante o processo de interação em enfermagem com os sujeitos participantes, reforçamos a concepção de que o desenho não foi apenas uma estratégia eficaz que permitiu a expressividade das crianças e dos adolescentes em relação às interações vivenciadas no cotidiano da sua hospitalização, mas, também, possibilitou momentos agradáveis aos sujeitos, permitindo a expressão de seus sentimentos, criatividade e imaginação, fazendo com que eles refletissem sobre sua situação de saúde-doença e hospitalização de uma forma sensível, contribuindo com o significado positivo sobre a hospitalização e o cuidado de enfermagem.

Acreditamos que as crianças e os adolescentes têm a capacidade de interagir verbalizando suas ideias, crenças e valores, assim como, dando significado às experiências vividas em seu cotidiano, que nesse caso refere-se à doença crônica e à hospitalização.

$\mathrm{Na}$ análise e reflexão dos significados encontrados, percebemos que o que mais chamou a atenção, não foi o fato dessas crianças e adolescentes vivenciarem experiências desagradáveis, como estar doente, longe de casa, exposto a procedimentos dolorosos, sentir tristeza, sofrimento, nervosismo, ter vontade de chorar, responder com agressividade em alguns momentos e perder a liberdade; pois todos esses aspectos são esperados no que diz respeito à resposta da criança e do adolescente à hospitalização. Mas, a capacidade desses indivíduos em reagrupar e transformar os significados em "experiências agradáveis" como fazer novas amizades, ter possibilidades de tratamento e cura, ter a percepção de ser cuidado com amor, carinho e paixão por médicos, enfermeiros, outros profissionais e pela família. Tudo isso, expressos através de seus lindos e criativos desenhos, permeados de significados e lições de vida. Mais do que nunca, essas crianças e adolescentes mostraram-se, em sua singularidade, como seres de potencialidades.

De toda a trajetória, os desenhos de Pri, Diego, Geandra e Emanuelle, bem como do adolescente RR, ficarão em nossa memória para sempre. Com essas imagens, vamos à busca de outros desafios, que possam, novamente, contribuir para a prática de cuidado em enfermagem pediátrica, trazendo o lúdico para o mundo da criança hospitalizada.

\section{REFERÊNCIAS}

1. Gabatz RIB, Ritter NR. Criança hospitalizada com Fibrose Cística: percepções sobre as múltiplas hospitalizações. Rev Bras Enferm 2007;60(1):37-41.

2. Lapa DF, Souza TV. A percepção do escolar sobre a hospitalização: contribuições para o cuidado de enfermagem.
Rev Esc Enferm USP 2011;45(4):811-7.

3. Dolce, LML, Pereira WJ, Andrade JS, Araújo ASA. Vamos cuidar com brinquedos?. Rev Bras Enferm 2010;63(6):950-5.

4. Falbo BCP, Andrade RD, Furtado MCC, Mello DF. Estímulo 
ao desenvolvimento infantil:produção do conhecimento em Enfermagem. Rev Bras Enferm 2012;65(1):148-54.

5. Barbier R. [homepage na internet] Escuta sensível na formação de profissionais de saúde Conferência na Escola Superior de Ciências da Saúde. Brasília: FEPECS, SES-GDF; 2002 [acesso em 23 nov 2012]. Disponível em: < http://www.barbier-rd.nom.fr/>

6. Bordoni T. Descoberta de um Universo: a evolução do desenho infantil [monografia na internet]. 2008 [acesso em 23 nov 2012]. Disponível em: < http://www.profala. com/arteducesp62.htm >

7. Mead $\mathrm{GH}$. The internet Encyclopedia of Philosophy [monografia na internet]. 2005 [acesso 23 nov 2012]. Disponível em: < http://www.iep.utm.edu/m/mead.htm >

8. Haguette TMR. Metodologias qualitativas na sociologia. 10. ed. Petrópolis: Vozes; 2005.

9. Trentini M, Paim L. Pesquisa convergente assistencial: um desenho que une o fazer e o pensar na prática assistencial em saúde-enfermagem. 2. ed. Florianópolis: Insular; 2004.
10. Minayo MC. Pesquisa social: teoria, método e criatividade. 27. ed. Petrópolis: Vozes; 2008.

11. Teixeira MA. Meu neto precisa mamar! E agora? Construindo um cotidiano de cuidado junto a mulheres-avó e sua família em processo de amamentação: um modelo de cuidar em enfermagem fundamentado o interacionismo simbólico. Florianópolis. Dissertação [Mestrado em Enfermagem]- Universidade Federal de Santa Catarina; 2005.

12. Carvalho LS, Camargo CL, Silva CA, Santos ACPO. O uso do interacionismo simbólico nas pesquisas de enfermagem pediátrica. Rev Enferm UERJ 2007;15(1):119-24.

13. Ministério da Saúde (Brasil). Resolução no 196, de 10 de outubro de 1996. Aprova as diretrizes e normas regulamentadoras de pesquisa envolvendo seres humanos. Diário Oficial da União 16 out 1996.

14. Friedmann A. O universo simbólico da criança: olhares sensíveis para a infância. Petrópolis: Vozes; 2005.

15. Maffesoli M. O conhecimento comum. Introdução à sociologia compreensiva. Porto Alegre: Sulina; 2007. 